\title{
ENHANCING HEAT TRANSFER COEFFICIENT AND BREAKDOWN STRENGTH OF MINERAL OIL BY (AL2O3 AND TIO2) NANOPARTICLES
}

\author{
${ }^{*}$ Mohammad M. Ali'
}

\section{Amer H. Majeed ${ }^{1}$}

1) Materials Engineering Department, College of Engineering, Mustansiriyah University, Baghdad, Iraq

\begin{abstract}
The aims of this paper study the effects of two types of nanoparticle on dielectric strength and heat transfer coefficient within mineral oil used in an electrical transformer. These nanoparticles (NPs) including (semi conductive $\mathrm{TiO} 2$ and insulating Al2O3), have been prepared with the same size and surface modification, it is shown that nano-particles enhance insulating and thermal properties of mineral oil as well as the degree of enhancement is dependent on the NPs concentration.
\end{abstract}

Keywords: Nanofluids, Mineral $\mathrm{Oil}, \mathrm{Tio}_{2}, \mathrm{AL}_{2} \mathrm{O}_{3}$, Nanoparticles, Dielectric Strength.

\section{Introduction}

Transformers are among the equipment's utilized in the transmission and distribution of transmission line; thus, it is the core of all systems since it is converting the voltage as well as the current with stability of frequency and power. Also, the transformer's lifespan is particularly significant in electrical and Electrical faults on the Transformer reduce its lifespan and this is often thanks to the low level of electrical insulation of the transformer [1-4]. The transformer's interior insulation is critical, as it decides whether the transformer is fit for entering the service or not. Mineral oils are used for isolating and cooling the transformer coils, as well as to provide an indication regarding the interior state of the transformer; thus, problems can be identified. As a result, if there is a problem with the oil, it should be treated either by refining or replacing, both of which are costly [5-7]. In addition, state-of-the-art nanotechnology makes it possible to produce and process materials with average crystallite sizes of less than $50 \mathrm{~nm}$. The thermal characteristics regarding such fluids with nanometer-sized particle suspension in conventional heat transfer fluids were much superior than those of traditional heat transfer fluids. These nano-fluids have an unprecedented combination of the two characteristics.

Most highly desired for thermal engineering applications: exceptional stability and high level of the thermal conductivity. Therefore, 'Nanofluids' is considered as a new class of heat transfer fluids which employs the dispersion of fine-scale metallic particles in the liquid of heat transport at in adequate size and volume fraction to significantly enhance effective heat transfer coefficient of the mixture. It's also used in enhancing electrical insulation, enhancing the chemical characteristics, dissolving gases, and enhancing viscosity. NPs of the transformer oil became as important because the medication for its diseases. (Al2O3and $\mathrm{TiO} 2$ )

*Corresponding Author: Malikali623@gmail.com 
Nanoparticles are that the most ordinarily used. It is more stable, less expensive, and simpler to create compared to other elementary substances [8]. Thermal performance and breakdown voltages can be improved [9-10]. The goal of this study is to see how NPs (semi-conductive and insulating) affect $\mathrm{AC}$ dielectric strength and heat transfer of transformer mineral oils.

\section{Experimental Methods and Test}

\subsection{Nanofluids Preparation}

In this preparation, DIALA mineral oil and NPs with a mean size of less than 50nm (which have been typically purchased) were employed. To satisfy clean oil demands, the mineral oil has been filtered to remove impurities, and a specific amount of chosen NPs (TiO2 and Al2O3) was weighed depending on the appropriate concentration. The NPs are after that mixed with surfactant and mineral oil, then stirred for $30 \mathrm{mins}$ at room temperature with a magnetic stir. Lastly, the mixture is ultra-sonicated for $2 \mathrm{hrs}$ to obtain well dispersed nanofluids. Also, the magnetic stirring aids in dispersing the nanopowders equally in the base fluid, yet the energy is insufficient for breaking any NP agglomeration. As demonstrated in "Fig. 1," an ultrasonic bath is utilized for breaking up the NP agglomerations. Table 1 summarizes the basic features of the 2 types of chosen NPs.

Table 1. properties of mineral oil NPs $\left(\mathrm{TIO}_{2}\right.$ and $\left.\mathrm{AL}_{2} \mathrm{O}_{3}\right)$

\begin{tabular}{lccc}
\hline $\begin{array}{c}\text { Materials } \\
\text { type }\end{array}$ & $\begin{array}{c}\text { Mineral } \\
\text { oil }\end{array}$ & $\mathbf{A L}_{2} \mathbf{O}_{3}$ & Tio2 \\
\hline properties & Dielectric & Insulator & Semiconductor \\
\hline conductivity & $10^{-12}$ & $10^{-12}$ & $10^{-11}$ \\
Density & 0.89 & 3.97 & 4.3 \\
Surfactant & - & Oleic & Oleic \\
modification & & acid & Acid \\
\hline
\end{tabular}

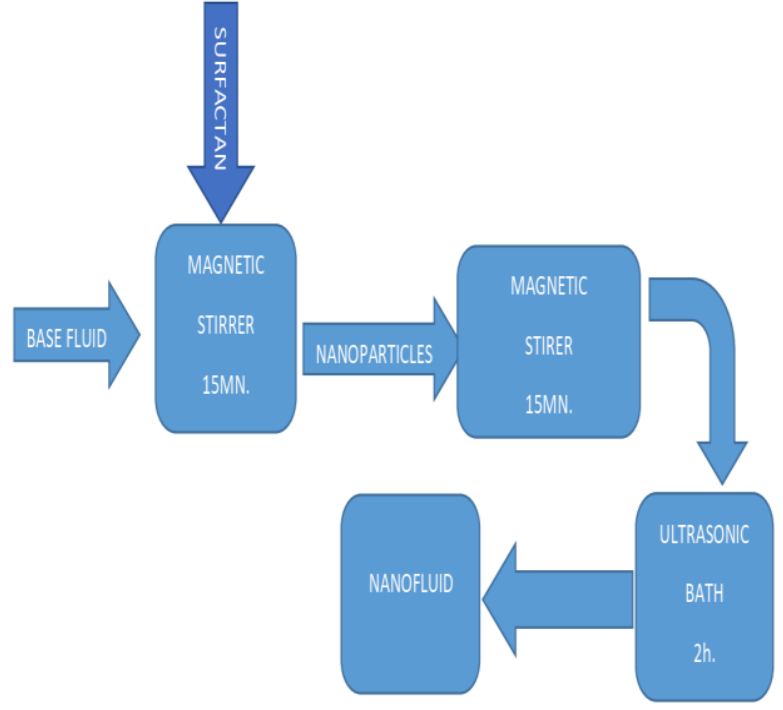

Figure 1. Stage of Nanofluid preparation

\subsection{Breakdown Voltage Test}

A new Nano-oil was obtained, but before it could be used, its electrical insulation had to be checked, AC break-down voltage has been measured in agreement with an IEC60156 standard [11]. "Fig.2", shows the breakdown voltage tester. The tester comprises of a test cell with a volume of (500) $\mathrm{mL}$ and an oil tester. The arrangement of the electrodes comprised of 2 copper hemispheres with a $12.5 \mathrm{~mm}$ diameter and a $(2.50 \pm 0.05) \mathrm{mm}$ gap distance between them. The clean oil is poured into a vessel. Also, the voltage between the electrodes is gradually applied, with the rate of rise controlled at $2 \mathrm{KV} / \mathrm{sec}$, and voltage at which sparking starts between electrodes is measured. Six burns were reported by the tester. Furthermore, the AC breakdown voltage was calculated using the average value. At room temperature, the complete experiment has been evaluated. 


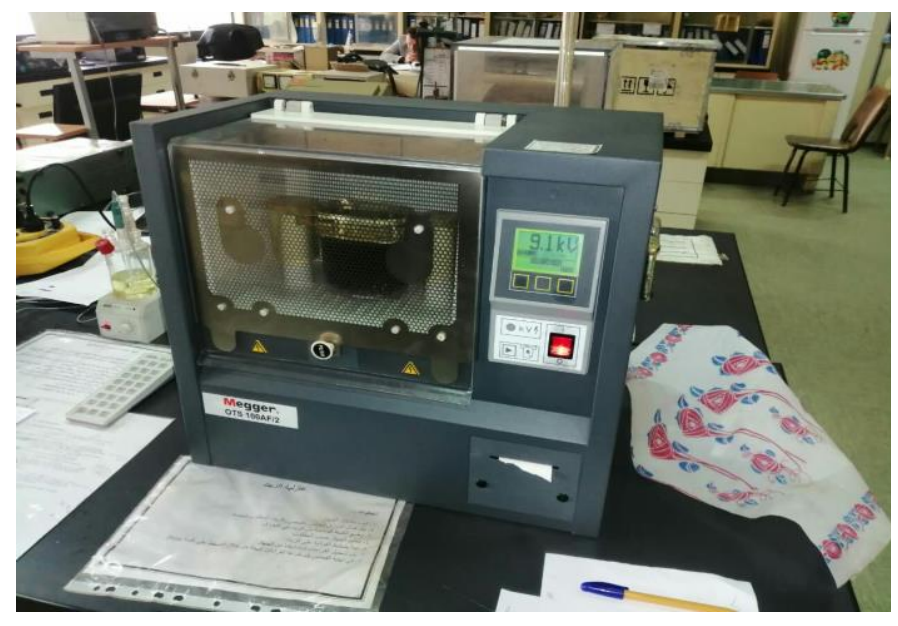

Figure 2. AC breakdown Voltage testers.

\subsection{Heat Transfer Coefficient}

Metals in solid form have been shown to have high thermal conductivity than fluids. Conduction of heat through a solid is orders of magnitude more than convection/conduction through a fluid. For example, Copper's thermal conductivity at the temperature of the room is approximately (700) times higher compared to that of the water and approximately $(3,000)$ times greater in comparison to that of engine oils [12]. As a result, fluids containing suspended solid particles should have much better heat transfer than typical heat transfer fluids [13]. Those fluids with Nanometer-sized particle suspension in conventional heat transfer fluids provided significantly high thermal characteristics compared to the ones of traditional heat transfer fluids and liquids, thanks to nanotechnology's ability for processing and producing materials with an average size which is not more than (50) $\mathrm{nm}$. The ratio of surface area to volume for particles with a diameter of (10) is (1000) times greater compared to particles with a diameter off (10) m. NPs have a substantially higher surface area than micro/macro-sized particles, which can enhance heat transfer capacities while also increasing suspension stability.

\section{Experimental Results}

\subsection{Break-down Voltage Measurement}

Six repeated breakdown measurements have been conducted for every one of the samples for generating average breakdown voltage. The breakdown voltage of Nano liquids is improved by adding nanoparticles; tests are conducted for the mineral oil as well as the prepared Nanoliquids with nanoparticle concentration values $(0.05,0.1,0.2$, and 0.3$) \mathrm{g} / \mathrm{L}$.

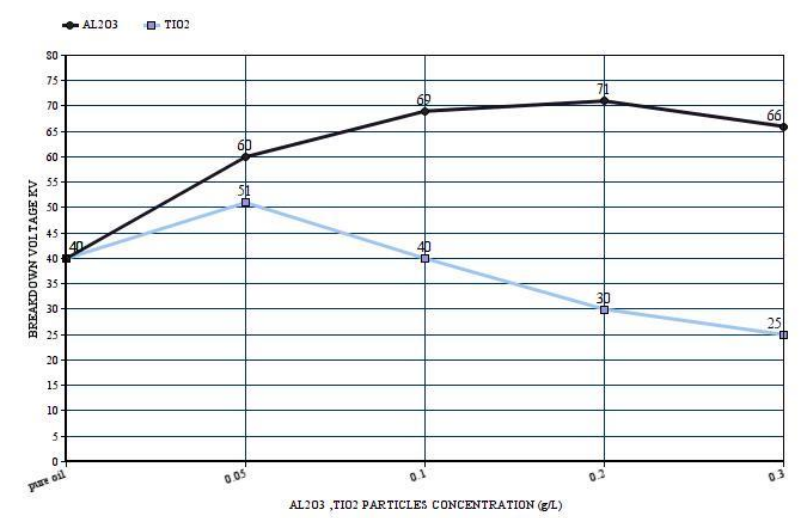

Figure 3. Breakdown strength of Nanofluids with (Tio2, AL2O3) NPS

\subsection{Heat Transfer Measurement}

One goal of this study is to enhance heat transfer that is related to transformer oil through converting it to Nanofluid. To better understand the application of this Nanofluid, an experimental device was designed, as shown in "Fig. 4". A controlled power source is used for powering the heater. On the heater surface and the opposite side, measure the entrance temperature (Ti) and output temperature (To). Take two temperatures every five minutes till attaining the thermal steady-state condition. The next formula might be used for calculating the coefficient of heat transfer. 
$h=\frac{q}{\Delta \mathrm{TA}}$

h $\left(W / m^{2}\right.$. K) represents coefficient of heat transfer, $q\left(\mathrm{~W} / \mathrm{m}^{2}\right)$ represents heat transfer amount, $\operatorname{Ti}(\mathrm{K})$ represents the heater surface's temperature, and $\operatorname{To}(\mathrm{K})$ represents surrounding fluid's temperature, and (A) represents the area of the heater. Higher $(h)$ means the better thermal performance of the insulating oil.

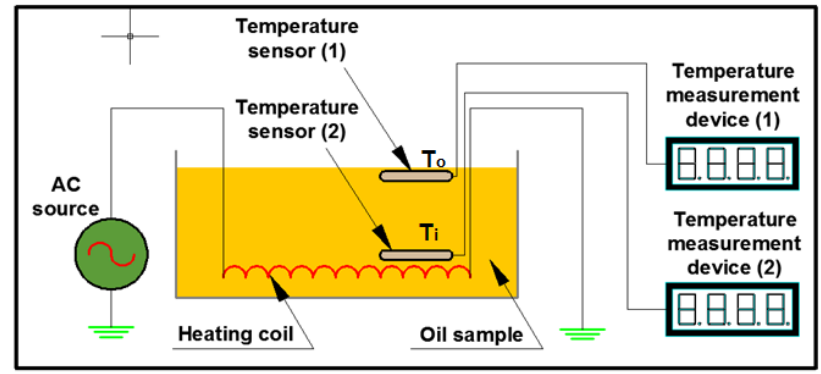

Figure 4. Experimental set -up for Heat transfer coefficient measuring.

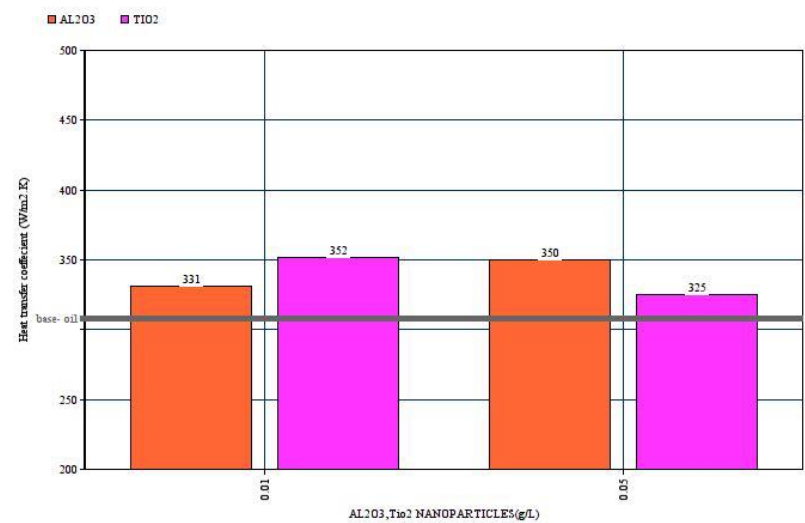

Figure 5. Heat transfer coefficient vs. NPs concentration for oil based Nano-fluids

\section{Results and Discussion}

The main aim of utilizing Nano-fluids is to increase breakdown voltage and heat transfer, the average breakdown voltage for Nano-fluids is higher, results are shown in "Fig. 3". Improvement was observed in all cases. The AC breakdown strength regarding mineral oil-based Nano liquids containing $\left(\mathrm{AL}_{2} \mathrm{O}_{3}\right)$ Nanoparticles is an observed improvement, reached a maximum at $0.2 \mathrm{~g} / \mathrm{L}$ then decreased at $0.3 \mathrm{~g} / \mathrm{L}$ but still higher than mineral oil. The effects of the additions od $\mathrm{TiO}_{2}$.

NPs on the AC break-down voltage of mineral oil has been an improvement at low particle concentrations, for concentrations that are higher than $0.05 \mathrm{~g} / \mathrm{L}$, and then the action of Nanofluids is similar or even less efficient in comparison to that of mineral oils due to the agglomeration and the sedimentation of $\mathrm{Tio}_{2}$ particles into the Mineral oil. The improvements of AC breakdown strength of nano-fluids as a result of larger volume fraction of the interface in most materials and the interaction between the surface of charged Nano-material's and the liquid molecules. The heat transfer coefficient of the oil-based Nano-fluids is increased. The results of $\left(\mathrm{Al}_{2} \mathrm{O}_{3}\right.$ and $\left.\mathrm{TIO}_{2}\right)$ Nano-fluids are shown in "Fig. $5 "$. For the pure oil, the measured value of $(h)$ is $308 \mathrm{~W} / \mathrm{m}^{2}$. K. After adding $0.01 \mathrm{~g} / \mathrm{L}$ of $\mathrm{Al}_{2} \mathrm{O}_{3}$ Nanoparticles, (h) increased to $331 \mathrm{~W} / \mathrm{m}^{2} \mathrm{~K}$. As weight fraction increases, $h$ continues increasing until it reaches $350 \mathrm{~W} / \mathrm{m}^{2} \mathrm{~K}$, at $0.05 \mathrm{~g} / \mathrm{L}$. For $\mathrm{TiO}_{2}$ Nanoparticles, (h) increases sharply at $0.01 \mathrm{~g} / \mathrm{L}$ reaches $352 \mathrm{~W} / \mathrm{m}^{2} \mathrm{~K}$, Then reduction in (h) has been observed at the concentration of $0.01 \mathrm{~g} / \mathrm{L}$, it is reduced to $325 \mathrm{~W} / \mathrm{m}^{2}$. K. At $(0.05) \mathrm{g} / \mathrm{L}$. The decrease in all cases achieved due to an increase of weight fraction is going to result in missing stability. Also, the heat transfer coefficient related to oil-based Nanofluids is better than mineral oil this may be explained with Brownian motion of NPs; Brownian motion can be defined as the random motion in fluid because of the collision of NPs with fast molecules in the fluid. This movement can achieve direct heat transfer between particles and cause convection of the surrounding fluid, as the NP's speed increases, heat might be transferred quickly through the fluid. 


\section{Conclusion}

In this paper, nanofluids are used for enhancements of breakdown strength and heat transfer performance of transformer oil, nanofluids are prepared by using $\left(\mathrm{AL}_{2} \mathrm{O}_{3} \mathrm{TiO}_{2}\right)$ nanoparticles (which were purchased traditionally) with surfactants within transformer oil. For each nanofluids sample, the breakdown strength and heat transfer are measured. It is found that the nanofluids sample has a higher breakdown voltage and heat transfer compared with the base oil. The NPs electronegativity as well as their involvement in attracting fastmoving electrons, which obstruct streamer propagation, results in a larger breakdown voltage. The process of breakdown is slowed because such electrons are captured. Brownian motion represents random motion of NPs in a fluid that results from collisions with fast molecules in a fluid; Brownian motion represents random motion of NPs in the fluid that results from the collisions with fast molecules in fluid. Heat might be quickly transferred via the fluid as the speed of NPs rises. As a result, such nanofluids not just have excellent cooling properties, yet they may also be used in highvoltage power transformers.

\section{Acknowledgements}

This paper is a part of a Master's thesis which in recent times was prepared at the Materials Engineering Dept., College of Engineering, Mustansiriya Univ. The author presents thanks with deep gratitude to anyone who made any aid, even if it was very small, during the performing of this research.

\section{Conflict of Interest}

The author confirm that the publication of this article causes no conflicts of interest.

\section{References}

1. Atiya, E. G., Mansour, D.-E. A., Khattab, R. M. \& Azmy, A. M. Dispersion behavior and breakdown strength of transformer oil filled with $\mathrm{TiO} 2$ nanoparticles. IEEE Trans. Dielectr. Electr. Insul. 22, 24632472 (2015).

2. Jeong, J.-I., An, J.-S. \& Huh, C.$\mathrm{S}$. Accelerated aging effects of mineral and vegetable transformer oils on medium voltage power transformers. IEEE Trans.

Dielectr. Electr. Insul. 19, 156161 (2012).

3. Mansour, D.-E. A., Atiya, E. G., Khattab, R. M. \& Azmy, A. M. Effect of titania nanoparticles on the dielectric properties of transformer oil-based nanofluids. in 2012 annual report conference on electrical insulation and dielectric phenomena 295-298 (IEEE, 2012).

4. Meshkatoddini, M. R. \& Abbospour, S. Aging study and lifetime estimation of transformer mineral oil. Am. J. Eng. Appl. Sci. 1, 384-388 (2008).

5. Lv, Y. et al. Effect of $\mathrm{TiO} 2$ nanoparticles on streamer propagation in transformer oil under lightning impulse voltage. IEEE Trans. Dielectr. Electr. Insul. 23, 2110-2115 (2016).

6. Du, Y. et al. Effect of semiconductive nanoparticles on insulating performances of transformer oil. IEEE Trans. Dielectr. Electr. Insul. 19, 770776 (2012).

7. Mansour, D.-E. A. \& Elsaeed, A. M. Heat transfer properties of transformer oil-based nanofluids filled with $\mathrm{Al} 2 \mathrm{O} \quad 3$ nanoparticles. in 2014 IEEE International Conference on Power and Energy (PECon) 123-127 (IEEE, 2014). 
8. Mergos, J. A., Athanassopoulou, M. D., Argyropoulos, T. G. \& Dervos, C. T. Dielectric properties of nanopowder dispersions in paraffin oil. IEEE Trans. Dielectr. Electr. Insul. 19, 1502-1507 (2012).

9. Liu, Q. \& Wang, Z. D. Streamer characteristic and breakdown in synthetic and natural ester transformer liquids with pressboard interface under lightning impulse voltage. IEEE Trans. Dielectr. Electr. Insul. 18, 1908-1917 (2011).

10. Liu, R., Pettersson, L. A. A., Auletta, T. \& Hjortstam, O. Fundamental research on the application of nano dielectrics to transformers. in 2011 Annual report conference on electrical insulation and dielectric phenomena 423-427 (IEEE, 2011).

11. ISO_354. International Standard International Standard. 61010-1 (C) Iec2001 2003, 13 (2003).

12. Eastman, J. A., Choi, S. U. S., Li, S., Yu, W. \& Thompson, L. J. Anomalously increased effective thermal conductivities of ethylene glycol-based nanofluids containing copper nanoparticles. Appl. Phys. Lett. 78, 718-720 (2001).

13. 13. Choi, S. U. S., Zhang, Z. G., Yu, Wl., Lockwood, F. E. \& Grulke, E. A. Anomalous thermal conductivity enhancement in nanotube suspensions. Appl. Phys. Lett. 79, 2252-2254 (2001). 